\title{
Projeto Defesa à Vida: A Psicologia na Escola de Ensino Fundamental
}

\author{
Rafaela Fava de Quevedo ${ }^{1}$ \\ Raquel Furtado Conte \\ Universidade de Caxias do Sul
}

\begin{abstract}
RESUMO - Esse relato de experiência baseia-se na intervenção realizada em uma escola pública do ensino fundamental. Através da descrição das atividades desenvolvidas foi possível compreender aspectos individuais e sociais, os quais afetam o indivíduo, em um ambiente considerado promotor de desenvolvimento. Os resultados apontam a eficácia das intervenções, atribuindo à escola um espaço protetivo. Com este estudo, espera-se contribuir para a reflexão sobre os métodos de intervenção em contextos escolares visando à promoção da saúde e ao favorecimento da busca por autonomia e a vida social.
\end{abstract}

Palavras-chave: psicologia escolar, formação do psicólogo, intervenção psicossocial, promoção da saúde

\section{Defense for Live Project: Psychology in an Elementary School}

\begin{abstract}
This experience's report is based on an intervention conducted at an elementary public school. Through the description of the activities, it is possible to understand individual and social aspects that affect the individual in an environment considered as a development promoter. The results show the effectiveness of the intervention and the school as a protective space. With this study we hope to contribute to reflections about the methods of intervention in school contexts that aim at health promotion and the search for autonomy and social life.
\end{abstract}

Keywords: school psychology, psychologist education, psychosocial intervention, health promotion

A atuação da psicologia na escola até a metade do século XX estava atrelada à preocupação com o conhecimento científico e baseada nos fundamentos médicos de concepção de doença. Nesse sentido, a abordagem de intervenção nas escolas estava voltada à resolução de problemas do desenvolvimento e da aprendizagem. Envolvia-se assim, com processos de categorização, segregação e marginalização do que é considerado "diferente" (Marinho-Araújo \& Neves, 2007). A partir de debates e discussões acerca da atuação dos psicólogos escolares, surgiu a Associação Brasileira de Psicologia Escolar e Educacional (ABRAPEE), em meados dos anos de 1980 e início de 1990. Essa associação tem contribuído para a formação da identidade do psicólogo escolar, os conhecimentos psicológicos que se aplicam à área e as possibilidades de atuação em espaços educacionais. No início do século XX, a preocupação com o modelo clínico e com os problemas de aprendizagem deixou de ser a única forma de concepção do psicólogo na escola. A preocupação e o objeto de investigação passaram também a incluir a compreensão das relações do indivíduo com o seu contexto social (Barbosa \& Araújo, 2010; Moreira \& Guzzo, 2014).

A proposta deste trabalho vai ao encontro do que diferentes autores (Franco \& Rodrigues, 2014; Guimarães, Aerts, \& Câmara, 2012; Rodrigues, Dias \& Freitas, 2010; Moreira \& Guzzo, 2014) conceituam como projetos de cunho preventivo e comunitário, os quais buscam articular a prática educativa à realidade sociocultural e resgatar a função da escola como agente de transformação social. Este relato de experiência aborda as intervenções realizadas no contexto de uma escola de ensino fundamental da rede pública estadual, situada no interior do Rio Grande do Sul, no período entre

1 Endereço para correspondência: Avenida Julio de Castilhos, 1051, sala 31, Centro, Caxias do Sul, RS, Brasil. CEP- 95010-003. E-mail: rafaelafaq@msn.com
2013 e 2014, totalizando um ano. Dessa forma, este trabalho se destinou a organizar os primeiros esforços de inserção da psicologia na escola, sendo que não havia sido realizado nenhum trabalho dessa categoria no local.

A partir das demandas emergentes, realizou-se revisão de estudos sobre psicologia e inserção na escola, prevenção e promoção à saúde, formando um plano de atuação nas temáticas revisadas. Para que esse projeto se efetivasse no local, em primeiro lugar foi realizado um entendimento institucional, abarcando o histórico da instituição, a estrutura física e funcional.

A experiência de estágio deu-se a partir do Projeto Defesa à Vida, coordenado por uma supervisora do Curso de Psicologia da Universidade de Caxias do Sul. Esse projeto prioriza intervenções protetivas e preventivas no sentido de minimizar a violência e a vulnerabilidade social e afetiva em diferentes populações e contextos. A carga horária para a atividade foi de seis horas semanais, divididas em dois turnos de atuação. A supervisão das atividades ocorreu semanalmente no período de uma hora.

A escola é uma instituição que acolhe diferentes sujeitos e famílias. Assim, há situações de vulnerabilidade social e afetiva, bem como situações de violência, nessa população. Cada escola em especial possui demandas específicas e que se vinculam ao seu caráter social. A partir desse entendimento, é necessário realizar uma análise adequada do funcionamento da instituição, para depois realizar uma proposta de intervenção que seja viável e se adapte às demandas vigentes.

A equipe diretiva da escola, ao aceitar o trabalho do psicólogo, abre possibilidades de promover a saúde frente às demandas que existem, bem como promover um espaço protetivo à sua principal clientela, ou seja, os alunos. Os alunos constituem grande parte do enfoque do trabalho, tendo em conta o fator de vulnerabilidade social e afetiva em 
que se encontram. Os aspectos referentes à vulnerabilidade emergem no contexto escolar e se presentificam nas questões comportamentais e de aprendizagem. De forma geral, pode-se pensar que a vulnerabilidade social é um fator que envolve situações contextuais, de ordem estrutural, familiar, pobreza, dificuldades ao acesso a saúde, privação de recursos, violência. Assim, a vulnerabilidade social se constitui de diferentes aspectos além do individual, abrangendo questões contextuais, culturais e coletivas (Sanchez \& Bertolozzi, 2007).

Cabe ressaltar que a proposta de intervenção baseou-se na possibilidade de desenvolver atividades que contemplassem a participação do psicólogo no cotidiano escolar. Pretendeu-se compreender os fundamentos e dinâmicas da escola e de sua equipe, bem como as situações sociais e pessoais dos alunos que possam interferir no processo ensino-aprendizagem e nas interações sócio-afetivas.

\section{Escola de Ensino Fundamental: Funcionamento Institucional}

Considera-se que a compreensão institucional constitui um elemento de primordial importância para a inserção in loco, atentando-se para o fato de que o grau de investigação e entendimento dinâmico componentes desse processo estão diretamente relacionados à eficiência para a realização dos objetivos propostos. O início da coleta de dados se deu no contato inicial com a direção da escola, ressaltando a necessidade de um profissional de psicologia nessa instituição. Este fato deve ser levado em consideração, visto que a aceitação do profissional bem como do projeto a ser desempenhado no contexto de intervenção determina a proporção da abertura à realização das tarefas propostas, e, portanto, a amplitude destas (Bleger, 1992). As demandas iniciais relatadas pelo diretor já continham um caráter que denotava vulnerabilidades, descrito por situações de agressões e violência (familiar e escolar).

Com o início das intervenções junto aos alunos (com grupos e aconselhamento individual), o trabalho começou a demarcar espaços simbólicos. Percebeu-se que, na oferta de um espaço para comunicar sentimentos e refletir sobre seus comportamentos, o adolescente passa a simbolizar por meio da linguagem o seu mundo interno e a comportar-se de maneira diferente (minimizando as expressões agressivas entre colegas). Os resultados, advindos em forma de feedbacks dos alunos, vieram também dos professores e da equipe diretiva, mencionando como os alunos estavam mais maduros, de forma a perceberem aspectos mais saudáveis frente aos comportamentos na escola.

Ainda, foram realizados atendimentos aos pais. Em cada situação, apresentava-se uma realidade familiar que corroborava também as formas de expressão dos adolescentes. Nas reuniões com os pais, eram apresentadas orientações, em uma abordagem psicoeducativa que enfocava a etapa da vida em que os filhos se encontravam, ou seja, a adolescência. Além do trabalho com alunos e pais, foi realizada assessoria informal com a equipe diretiva e os professores. Aos poucos, o espaço da psicologia foi adentrando novos espaços da escola, como, por exemplo, conselhos de classe. Dessa forma, podia fazer-se presente e atuante nas reuniões e decisões referentes às situações emergentes da escola.

Quanto às perspectivas trazidas pelos membros da instituição, no que se refere às formas de contribuição da psicologia no contexto educacional, concordou-se que a prática do psicólogo tem caráter mais amplo e visa à instituição como um todo (professores, pais, comunidade). As conversas realizadas na escola, tanto com o diretor quanto com professores e funcionários, foram abertas, no sentido de recolher dados tanto da escola como das relações de trabalho que se estabelecem ali. De acordo com as demandas sobre violência, pôde-se pensar num trabalho direcionado à origem do conflito, avaliando através do sistema escolar o que é considerado violência (espaço para psicoeducação), a fim de que a própria instituição amplie sua vida acerca do fenômeno e suas implicações multifacetadas. Salienta-se também a tentativa de aproximar os pais da comunidade escolar como um fator protetivo às dificuldades que se apresentam no momento. A distância dos pais na participação escolar é entendida como um fator que põe em risco o desenvolvimento social e psicológico dos adolescentes.

Frente a isso, propuseram-se à equipe diretiva objetivos voltados a aproximar a família da escola, sendo ambos os espaços entendidos como fatores de proteção na construção subjetiva do sujeito (Bronfrenbrenner, 1979/1996); criar atividades ou estratégias que incentivem a participação dos pais na trajetória escolar de seus filhos; e, mobilizar nos alunos o sentimento de reconhecimento familiar, sendo que o empenho na realização das atividades pode promover maior integração do adolescente com sua família.

Ainda pensando nos objetivos do trabalho da psicologia, é necessária uma visão da diversidade, considerando as subjetividades dos indivíduos que fazem parte dessa instituição. Isso se materializa em uma nova demanda de trabalho, centrada não mais na homogeneidade, mas englobando diferenças de raças e etnias, entre as subjetividades e as realidades sociais. As desigualdades sociais se manifestam nas diferenças de oportunidades de escolhas sociais e profissionais, afetando a vida dos indivíduos nos grupos internos e externos à escola.

A mudança de um enfoque que privilegiava os problemas de comportamento e de aprendizagem para um enfoque preventivo foi uma conquista da educação e da psicologia, ao se oporem à visão reducionista para objetivar práticas amplas, em que a saúde mental tem relevância e o desenvolvimento integral dos alunos é responsabilidade da instituição de ensino. A psicologia na escola pode trabalhar com a prevenção, possibilitando diálogos abertos e inserindo a escola como um fator de proteção e cuidado para seus alunos. Corroboram esse entendimento Almeida e Lisboa (2014), Franco e Rodrigues (2014) e Guimarães et al. (2012), que sugerem que as intervenções devem minimizar e prevenir o sofrimento psíquico, propiciando e desenvolvendo, assim, estratégias e relações interpessoais saudáveis.

Nesse sentido, o olhar do psicólogo deve ser atento ao processo de mudanças, tendo clareza de que as intervenções são de real ajuda para o grupo no qual seu foco está inserido. Cada escola constitui-se de valores, preceitos, normas e formas de educação, sendo composta por pessoas diferentes. São essas crenças que formam a cultura local, bem como a 
cognição social, as quais determinam e afetam diferentes comportamentos. As atitudes estão associadas às crenças e são formadas pela aprendizagem condicionada ou por estímulos vivenciados como afetivamente positivos. Os processos grupais podem levar os indivíduos a modificarem seus comportamentos e interferem ao mesmo tempo nos processos de identificação grupal. Efeitos positivos na autoestima, no autoconceito e na identidade social são possíveis de serem percebidos em trabalhos com grupos (Ferreira, 2010). A abrangência dos aspectos externos ao indivíduo bem como dos aspectos internos (subjetivos) deve ser levada em conta na formulação de intervenções. A pretensão é de que as intervenções possam prevenir e fortalecer o manejo dos membros da escola entre eles e os alunos (incluindo os seus respectivos pais), bem como auxiliar o desenvolvimento das habilidades sociais e afetivas dos alunos consigo mesmos e com seus pares, considerando as demandas da instituição.

\section{Intervenções: Descrição das Atividades Realizadas}

\section{Intervenções Grupais}

As intervenções grupais foram de cunho reflexivo, consideradas por Zimerman e Osório (1997) como grupos de aprendizagem, e seguiram os seguintes objetivos: compreender através de escuta as demandas dos alunos em um espaço de respeito às diferenças, fortalecendo, assim, a autoestima e a valorização de si; desenvolver um trabalho que privilegiasse a identificação de conteúdos trazidos pelos alunos como pontos importantes de intervenção; abordar assuntos referentes à adolescência e às problemáticas vivenciadas atualmente pelas turmas; identificar os fatores de risco e potencializar aqueles de proteção individuais e da escola; possibilitar um espaço para comunicação respeitando o tempo de cada um, bem como as diferenças individuais e aspectos em comum.

Grupo reflexivo de meninas. Foram realizadas quatro sessões quinzenais com 14 meninas com idade entre 13 e 16 anos. Características do grupo: fechado; homogêneo quanto ao sexo e período do desenvolvimento, ou seja, adolescência; e heterogêneo quanto à vulnerabilidade social. A demanda inicial partiu da escola, sendo uma turma que apresentava problemas de comportamento em sala de aula (muita conversa, pouca concentração nas disciplinas e falta de respeito com professores). O primeiro encontro se desenvolveu com o objetivo de formação da identidade grupal e integração dos membros. Utilizou-se a técnica descobrindo os nomes e apresentando a qualidade do outro (Ministério da Saúde, 2000). Esse primeiro momento também foi importante para criar o enquadre e o contrato psicológico (Zimerman \& Osório, 1997), priorizando o sigilo e participação de todas. Seguindo as técnicas sugeridas no "Manual do multiplicador" (Ministérios da saúde, 2000), o segundo encontro abordou temáticas sobre a diversidade, bem como questões de sexualidade, emergindo delas temas que foram discutidos pelo grupo. No terceiro encontro, discutiram-se temas emergentes a partir de um disparador grupal, utilizando-se frases sobre diversos temas recorrentes à adolescência como: sexualidade, bullying, agressividade, amizades, relacionamentos interpessoais e familiares, escola, entre outros. $\mathrm{O}$ assunto mais discutido foi referente ao bullying. Com boa expressão verbal, foi realizada troca de experiências envolvendo o sofrimento decorrente do bullying. A partir disso, trabalhamos estratégias como, por exemplo, responder brincando ou não dar atenção. No quarto e último encontro, revisaram-se os conteúdos que trabalhamos, bem como solicitamos que se atribuísse um feedback ao processo como um todo. Os objetivos foram atingidos, houve interesse e participação, propiciando momentos de discussão ricos para a construção da identidade e integração do grupo. Com o movimento do grupo, este se fortaleceu na resolução de problemas e no desenvolvimento da capacidade de auxilio, de respeitar as falas e o espaço de cada um, em uma comunicação mais assertiva.

Grupo reflexivo de meninos. Foram realizadas quatro sessões quinzenais com 10 meninos com idade entre 13 e 15 anos. Características do grupo: fechado; homogêneo quanto ao sexo e período do desenvolvimento, ou seja, adolescência; e heterogêneo quanto à vulnerabilidade social. $\mathrm{O}$ encontro inicial favoreceu um bom vínculo, além do enquadre da valorização do sigilo. Após, realizou-se uma dinâmica de apresentação. No segundo encontro, ocorreram duas dinâmicas visando à participação e à união. Ambas foram concluídas, sendo que, na discussão, os meninos destacaram a necessidade de maior união entre eles. Esse encontro foi gerador para o trabalho sobre habilidades sociais, abordando-se também as diferenças de cada um e o respeito frente ao outro. O terceiro encontro ocorreu a partir de uma dinâmica disparadora de debates. Entre os assuntos explorados, estavam bullying, sexualidade, sentimentos (tristeza, raiva, medo), comportamentos em diferentes situações, drogas e visão da escola. No quarto e último encontro, teve-se como objetivo realizar um resgate dos temas discutidos nos encontros anteriores, bem como a valorização de cada membro. É possível destacar que, embora, tenham sido realizados poucos encontros, houve um importante crescimento no grupo, que se tornou perceptível a partir das trocas afetivas e sociais e no compromisso com o sigilo construído.

Grupo do turno inverso. Confeccionou-se um cartaz a partir do qual se divulgou que os alunos interessados e disponíveis poderiam inscrever-se para participar do grupo, que ocorreu no turno inverso ao horário em que estavam matriculados. Esse processo se deu visando à autonomia e à independência do aluno a participar do grupo, responsabilizando-se pelo compromisso. Além disso, foi enviado aos pais uma carta de consentimento, esclarecendo que a atividade a ser realizada na escola visava trabalhar com conteúdos referentes à adolescência. Foram realizadas sete sessões semanais com seis adolescentes de idade entre 13 e 15 anos. O grupo caracterizou-se como aberto e heterogêneo quanto ao sexo e à vulnerabilidade social e afetiva. Os encontros foram definidos com as seguintes propostas: apresentação de todos e formação do sigilo e enquadre (encontro um); abordagem da temática gênero e sexualidade, trabalhando questões de preconceito, de vantagens e desvantagens de ambos os sexos, bem 
como questões de homossexualidade, bissexualidade e heterossexualidade (encontro dois); identidade pessoal, grupal e familiar (encontro três); assertividade, passividade e agressividade, priorizando a compreensão de que qualquer comportamento gera consequências para si e para o outro. Foi possível observar a prevalência da agressividade na emissão de respostas dos participantes. Uma hipótese é a presença de uma cultura familiar que resolve seus conflitos com uso da violência, transmitindo aos filhos que essa é uma forma eficaz de lidar com as situações. A partir disso, trabalharamse práticas assertivas a partir de uma proposta em que cada dupla criava situações e respostas possíveis (encontros quatro e cinco). Cada situação foi interpretada, sendo discutidas as alternativas mais assertivas (encontro seis). No fechamento, realizou-se a atividade "a mala" (Ministério da Saúde, 2000) em que cada participante recebeu post its coloridos para escrever o que levou consigo nesse percurso do grupo, ou seja, a 'bagagem'. Algumas palavras se destacaram, como bom humor, respeito, responsabilidade, capacidade, confiança e compreensão. Como feedback, percebeu-se o desenvolvimento de um melhor manejo de situações sociais de convivência, auxiliando a lidar com a ansiedade e agressividade. Esse grupo apresentou bons níveis de coesão grupal (Zimerman \& Osório, 1997), havendo verbalizações do desejo de continuar com o grupo, o que sugere que houve um espaço real para esses adolescentes se sentirem valorizados e ouvidos nas suas demandas e dificuldades.

Entendimento quanto aos grupos. O objetivo de formar grupos foi de proporcionar aos adolescentes a oportunidade de vivenciarem a experiência de serem membros de um grupo que se constituísse em um espaço no qual pudessem elaborar as tensões engendradas pelas atividades, a relação com os professores e entre os colegas (Osório, 2003). Grupos constituem um espaço de explicitação de crenças e valores, permitindo experiências que possibilitem o acesso à cultura de cada membro e à cognição social. De acordo com Ferreira (2010), enquanto não se puder refletir sobre esses conceitos, as atitudes não poderão ser modificadas. Nos grupos desenvolvidos, após uma breve apresentação inicial, a coordenadora do grupo, papel exercido pela estagiária, estabeleceu o enquadre grupal, enfatizando sigilo, duração e frequência. O enquadre é conceituado como a soma de todos os procedimentos que normatizam e possibilitam o processo (Zimerman, 2000).

Outro aspecto importante no processo grupal é o papel do coordenador. O coordenador está ali para ajudar os membros a refletirem, não esperando que o processo ocorra de forma pré-determinada. Cada grupo tem seu momento, suas ansiedades básicas que acabam por definir muitos dos comportamentos que configuram sua totalidade. Espera-se do coordenador que tenha paciência para que conflitos, ansiedades, defesas e identificações possam emergir para que se possa realizar a intervenção adequada. Outra característica importante é a função continente. O coordenador deve acolher as várias identificações projetivas que nele recaem (Zimerman, 2000). A exemplo, cita-se a exacerbada projeção do grupo de meninos no que diz respeito à sexualidade, o que ocorria abertamente na forma de perguntas pessoais.

Vislumbrando a prevenção de fatores de risco, destacouse a violência como um conjunto de comportamentos e ações que ocorrem em diferentes contextos sociais, como escola, família e círculo de amigos (Guimarães et al., 2012). Existem vários fatores de risco para a expressão da violência, sendo um deles a ausência de aprendizagem pelas crianças sobre como lidar com seus sentimentos agressivos, o que resulta na dificuldade de conter suas angústias e na necessidade de descarga imediata de suas tensões. Em outras palavras, a violência é uma descarga de emoções que não são nomeadas ou compreendidas. No caso da adolescência, as emoções podem passar despercebidas tanto pelos pais como pelos próprios adolescentes. Pelas mudanças decorrentes do processo de amadurecimento e passagem para outra fase do ciclo de vida, o comportamento é expresso de maneira a ocultar ou suprir seus sentimentos e dúvidas (Franco \& Rodrigues, 2014).

Justificam-se as temáticas abordadas neste trabalho como representantes de aspectos protetivos e saudáveis nos adolescentes. Dessa forma, tem-se que o "ensino das habilidades sociais como prevenção primária do uso de drogas, da gravidez na adolescência e da violência, bem como para prevenção da AIDS, promoção da autoestima e da autoconfiança" (Rodrigues et al, 2010, p. 832) propicia um espaço para a discussão desses temas, o que denota a apropriação dos adolescentes diante das temáticas. Além disso, o trabalho com comportamentos assertivos permite elucidar uma série de boas respostas diante de situações que serão vivenciadas ao longo da vida, de forma que a pessoa poderá emitir respostas mais adaptadas, ou seja, assertivas. A assertividade passa a ser um conteúdo trabalhado frente às demandas dos alunos. As situações de violência familiar geram sentimentos e comportamentos agressivos na escola e em outros ambientes. Compreender esses sentimentos permite que eles busquem novas formas de expressá-los (Del Prette \& Del Prette, 2011; Guimarães et al., 2012). Nesse sentido, o treino assertivo vem a ser uma intervenção promotora de saúde, adequada aos objetivos do Projeto de estágio. Um tema presente com frequência entre os grupos é o bullying, sendo este considerado uma forma de violência na escola, tanto na sua forma física (agressões) quanto psicológica (apelidos, insultos e atitudes preconceituosas). O bullying gera sofrimento e traz consequências negativas aos relacionamentos e à aprendizagem (Almeida \& Lisboa, 2014). No trabalho com os grupos, percebeu-se que esse tipo de violência vinculava-se às estratégias em respostas comportamentais, atuando em um caráter passivo-agressivo. Assim, as intervenções amparadas no reconhecimento e desenvolvimento de habilidades sociais permitiu que se desenvolvessem características já descritas por Almeida e Lisboa (2014), sendo elas: “empatia, controle das emoções, assertividade, sociocognição, cooperação, responsabilidades, expressão de sentimento positivo, comunicação e socialização" (p.69). As autoras ainda reforçam a necessidade de intervenções e programas de atuação que valorizem o treinamento de habilidades sociais. Essas intervenções promovem proteção para o público infantil e adolescente, não somente em casos de bullying, mas na construção conjunta de comportamentos eficazes na resolução de problemas interpessoais e na promoção de resiliência. 


\section{Aconselhamentos}

Particularmente em âmbito educacional, o aconselhamento objetiva a promoção de um melhor ajustamento do indivíduo, no sentido de desenvolver suas potencialidades. Nesse sentido, os aconselhamentos tiveram os seguintes objetivos: estabelecer um local de escuta individual visando acolher demandas pontuais; intervir de forma breve visando à autonomia dos indivíduos e da instituição, envolvendo também a sugestão de comportamentos e estratégias de enfrentamento adaptativas; oferecer um espaço continente que atue como fator de proteção e em que se abordem aspectos e ferramentas saudáveis para cada caso; realizar encaminhamentos quando necessário. Conforme Scheeffer (1993), o aconselhamento psicológico representa um modo de intervenção que se constitui em uma tentativa de propiciar possibilidades na modificação de atitudes e comportamentos, na busca de resoluções de diferentes problemáticas (educacional, profissional, vital), bem como do desenvolvimento dos recursos pessoais. As demandas apresentadas pelos adolescentes foram diversificadas. No entanto, o assunto que mais evidenciou-se foi o uso de drogas. Adotou-se especialmente a postura de enfatizar o risco do abuso dessas substâncias, elucidando a abordagem psicofarmacológica e as consequências ao sistema nervoso.

Segundo Trindade e Teixeira (2000), o aconselhamento psicológico é uma relação de ajuda que contribui para a adaptação do indivíduo em situações emergentes. Sua finalidade é a promoção de bem-estar e autonomia frente às dificuldades. Logo, é necessário abordar recursos e atividades adaptativas a fim de construir manejos adequados às situações que apresentem. Diante disso, o aconselhamento se mostrou como um espaço para o autoconhecimento, em que os adolescentes tiveram a oportunidade de refletir sobre suas escolhas/comportamentos e emoções, assim como descobrir as habilidades e recursos de que já dispunham e passavam despercebidos, utilizando esses aspectos como fatores de proteção. Pensando dessa maneira, o aconselhamento se centraliza nas subjetividades, nas potencialidades e nos aspectos psíquicos saudáveis dos indivíduos, cujo desenvolvimento possibilite a melhora em determinado aspecto, conforme a conflitiva emergente. Estabelece-se como uma atividade educativa, preventiva, de apoio, situacional e voltada para a resolução de problemas (Scheeffer, 1993).

\section{Encontro de Pais}

Os pais que participaram desse encontro mostraram-se preocupados com a educação e os comportamentos dos filhos. Perceberam e nomearam as mudanças no comportamento e nas atitudes dos filhos e a entrada na adolescência, o que permitiu um trabalho psicoeducativo e a reflexão sobre como eles próprios vivenciaram essa fase. Criou-se, assim, um espaço para falar sobre as diferenças entre os filhos. Cada um tem seu tempo, seu processo, uns avançam mais, outros menos. À família cabe aceitar isso e promover um ambiente facilitador para a emergência de aspectos saudáveis.

\section{Discussão}

Diante do conjunto de práticas possíveis e abordadas aqui de forma sucinta, é possível realizar um entendimento quanto às vivências no espaço escolar. A ocupação do espaço da psicologia deu-se de forma restrita e limitada. A partir do espaço que é proposto para ocupar a posição na escola, o estagiário deve permitir-se experimentar e abrir-se a novas possibilidades. De acordo com o relatório da UNESCO (in Abramovay, 2002), a escola deixou de ser um lugar seguro e promotor do desenvolvimento devido ao crescente número de violência entre alunos e alunos e professores. Uma forma de o psicólogo intervir nessa instituição deveria englobar a ampliação de suas atividades com pais, professores e alunos. Dessa forma, promoveríamos sua inclusão com práticas que viabilizassem todo os ambientes que interferem na formação dos alunos. A prática exclusivista com alunos reforça a exclusão desses atores, que não se sentem atuantes no contexto escolar. O psicólogo que atua no ambiente escolar, seja no trabalho preventivo ou na atenuação de demandas, deve estimular a comunicação aberta e as trocas entre os atuantes na comunidade escolar a partir de uma escuta empática. A fim de dinamizar os espaços, especialmente grupais, utilizaram-se atividades de reflexão e construção especialmente no que se refere às habilidades sociais, visto que se destacaram as conflitivas interpessoais. As habilidades sociais priorizam a tomada de consciência no que diz respeito às possíveis respostas, tomando por excelência respostas e comportamentos assertivos, ao invés de agressividade ou passividade (Del Prette \& Del Prette, 2011). Dessa forma, as intervenções tiveram a finalidade de desenvolver e problematizar com os adolescentes as dificuldades por eles vivenciadas, no sentido de reflexão sobre o papel de cada um e no desenvolvimento de habilidades ou recursos na incidência de situações de risco. Nesse sentido, Franco e Rodrigues (2014) consideram relevantes os recursos e mudanças dos adolescentes nas capacidades e habilidades pessoais, em busca de superar eventuais comportamentos de risco.

Também é importante salientar a presença de sentimentos ambíguos presentes nos adolescentes. Tanto no que remete ao enfrentamento de bullying quanto a sentimentos e relacionamentos positivos, como amizades, há demasiadas dúvidas quanto a nomear os sentimentos e expressar um comportamento compatível com esses sentimentos. Diante disso, fez-se importante intervir na presença desses sentimentos ambíguos, construindo maneiras de expressar da melhor forma aquilo que é sentido. Assim, as participações grupais foram essenciais para absorver estratégias utilizadas pelos colegas e que podem ser adaptadas às suas próprias realidades. Tendo um ambiente acolhedor e de possibilidades, tornou-se possível vivenciar essas experiências de troca e crescimento interpessoal. Marinho-Araujo (2010) articula que o trabalho do psicólogo na escola deve "provocar a re-significação das demandas e criar novos espaços para interlocução e circulação de falas e discursos dos sujeitos" (p. 27). A criação desses espaços de interlocução se fez nos grupos com os alunos. O espaço destinado à fala, à discussão, ao manejo de experiências comportamentais e emocionais reflete um movimento que transforma a vida dos participantes dos grupos bem como de todo o contexto 
escolar, que revê o significado do aluno indisciplinado. Em outras palavras, pode-se pensar que o foco na atenuação e prevenção se manifesta na instituição e no indivíduo, visto que ambos influenciam a construção do espaço do qual fazem parte. Sant'Ana, Costa e Guzzo (2008) apontam que a escola tem um poder institucionalizado que visa zelar pela vida das crianças e dos adolescentes. Para tanto, deve oferecer condições e cuidados que favoreçam o desenvolvimento psicossocial saudável. A psicologia, nesse sentido, vem a construir espaços de interlocução que dão voz às demandas coletivas e individuais por meio de um trabalho voltado a elevar os fatores de proteção que uma escola pode ter, como, por exemplo, movimentando a rede de apoio em defesa da criança, bem como sendo ouvinte e continente às problemáticas que ocorrem.

Quanto à postura dos professores, percebeu-se que, nessa escola, estes tendem a não serem passivos. Pelo contrário, realizam tentativas para lidar com as dificuldades dos alunos (especialmente com temas referentes a agressividade e comportamento). Entretanto, as estratégias passam a ser reproduzidas conforme suas vivências e experiências. Como consequência, com frequência, o comportamento do aluno acaba sendo reforçado pela ineficiência da atitude do professor. Os professores entendem que a problemática do aluno que se expressa na escola está relacionada ao seu contexto familiar. Há um interesse dos professores e da equipe diretiva em entender a história do aluno e as dificuldades que ele vivencia e que influenciam seus comportamentos dentro e fora da escola. Esse interesse é positivo na medida em que se compreendem as vulnerabilidades da escola, dado seu público distinto. Por outro lado, há um julgamento crítico quanto às situações familiares, visto que todas as dificuldades passam a ser atribuídas às vulnerabilidades do contexto familiar. Isso favorece a perspectiva que exime o trabalho dos educadores no investimento maior nesses alunos, amparado na crença de que não é possível ajudar nesses casos. Ainda, esse funcionamento se repercute também na dificuldade de conviver com a diversidade. A escola recebe alunos inseridos em diferentes situações sociais e familiares. Emerge, na escola, um ambiente favorável à criação de rótulos quando se trata de diferenças pessoais ou grupais: "esse é especial"; "o sétimo ano é o pior"; "nunca tivemos oitavas séries tão ruins"; "é um drogado mesmo" (sic.). Na verbalização dessas falas, o professor desacredita a possibilidade de mudança que a escola pode operar, sendo que, por essa perspectiva, a educação e a constituição do sujeito é oriunda do espaço familiar apenas. Por vezes, as atitudes dos professores passam a ser ambivalentes: por um lado, olham para a criança e, por outro, criam rótulos que dificultam qualquer tipo de solução de problema (Sant'Ana et al, 2008).

No quesito das regras da escola, estas devem ser repensadas, ter seus sentidos e validade discutidos, comparando-se com outros locais que também são amparados por regras. O uniforme, por exemplo, acabou por ser uma regra constantemente repudiada pelos alunos. Diante da intervenção da estagiária, os professores se mobilizaram a construir um uniforme (camisetas) para si, com o logotipo da escola, incentivando o uso de todos. Esse fator evidencia que um profissional da psicologia em ambiente escolar pode ser transformador de aspectos instituídos. Nesse sentido, a intervenção do psicólogo na escola tem caráter instituinte, da ordem da transversalidade, como um elemento novo, gerando devires e atualizando práticas e dinâmicas reproduzidas (Baremblitt, 2012).

Para Moreira e Guzzo (2014), as intervenções em um ambiente escolar devem abarcar a todos que dele participam. Isso se repercute na importância de trabalhar junto às famílias, junto aos professores e junto às crianças e aos adolescentes. Assim sendo, as ações realizadas na escola configuraram uma totalidade interventiva, embora algumas atividades tenham se dado com públicos específicos, repercutiram em todos os atores que envolvem-se nessa instituição.

Salienta-se que as intervenções realizadas mostram-se consoantes ao fazer do psicólogo levando em consideração aspectos éticos e em prol da saúde psicológica dos que fazem parte da instituição. Isso se articula aos estudos (Almeida \& Lisboa, 2014; Franco \& Rodrigues, 2014; Marinho-Araújo, 2010; Sant'Ana et al., 2008) que abordam a temática escolar, situações de violência e sobre a fase de vida em que se encontram os participantes da escola (pré-adolescência e adolescência). Há uma expectativa de que de alguma forma o trabalho do psicólogo fora percebido como importante no ambiente escolar, mas que esse profissional sozinho nada faz, necessitando de apoio e estrutura interdisciplinar, em que todos possam atuar pela melhoria das dificuldades.

\section{Considerações Finais}

Argumenta-se que as atividades realizadas foram planejadas com intuito de desenvolver aspectos saudáveis e relações sadias, sendo a escola um local de encontro de culturas e diversidade. Assim, o trabalho privilegiou aspectos de atenuação de dificuldades, bem como a promoção da saúde psicológica. As práticas na escola foram extremamente válidas, dados os resultados positivos frente às intervenções da psicologia no sentido da saúde e da preservação da qualidade de vida. Ainda, vale destacar a importância de movimentar a criatividade quanto aos processos interventivos, na criação de espaços para acolher os sujeitos e suas demandas de maneira completa. Dessa forma, visualizase a necessidade de flexibilizar estratégias, ou seja, recorrer a estratégias que tenham significado no contexto de trabalho e para aquela clientela específica. Quanto aos aspectos práticos, destaca-se a oportunidade de aprendizados em diferentes níveis: no fazer psicológico associado ao aparato teórico, no aprimoramento de características profissionais, como a empatia, a qualidade de escuta, e na contribuição do trabalho da psicologia na escola. Além disso, assumir o papel de psicóloga, encontrando brechas a fim de valorizar o trabalho e a atuação das práticas possíveis. Reconhecese como dificuldade o processo de distanciamento dos alunos, já que estes se vincularam com a estagiária de forma saudável. Esse vínculo foi necessário para auxiliá-los em suas dificuldades, já que a confiança foi um facilitador para a expressão de situações que vivenciavam. Aos poucos, foi possível realizar esse distanciamento, ao mesmo tempo sendo empática e produzindo vínculos saudáveis.

No que tange ao sigilo profissional, percebeu-se algo do imaginário dos professores quanto ao trabalho da psicologia, 
como ambiguidades em que se oferecia abertura, mas, ao mesmo tempo, ocorriam tentativas de controlar o trabalho. Observaram-se, no início, dificuldades em aceitar o sigilo, mesmo quando informados de sua finalidade. Aos poucos, houve maior confiança no trabalho da psicologia e o sigilo passou a ser aceito e respeitado. Como sugestões, destacase a importância de o psicólogo, no trabalho em contextos escolares e/ou públicos, especialmente em trabalhos de promoção de saúde, trazendo para o espaço da escola um local protetivo aos alunos. Como estratégia, é necessário incluir todos os envolvidos na escola em intervenções que gerem dinamização e compreensão do papel de cada um. Além disso, deve-se evitar cair na descrença de que certas situações não têm solução, visto que isso reforça essa perspectiva. Cada um pode atuar de maneira diferente na busca por um ambiente saudável e que priorize a saúde social e psicológica. O psicólogo deve atuar de forma plena, não se restringindo a demandas prontas ou intervenções focais prescritas. Cada processo interventivo na escola elucidou a necessidade de flexibilidade da estagiária, realizando diferentes relações e interconexões. Os resultados advindos do trabalho devem ser atribuídos a essa característica, assim como a uma postura proativa, que evoque busca ativa na construção de intervenções e também na prática destas. Mostra-se como limitação a escassa participação dos pais junto às intervenções planejadas para esse grupo. Entretanto, esse dado é reflexo do distanciamento entre família e escola. Em um trabalho futuro, seriam necessários maiores esforços para promover a participação tanto da escola como da família. Sugerem-se também atividades educativas para a promoção da saúde. Nesse sentido, o psicólogo que atua junto à escola pode colaborar com intervenções de aproximação, valorizando e fortalecendo esses vínculos, consequentemente reverberando na saúde psicológica de todos.

\section{Referências}

Abramovay, M. (2002). O bê-a-bá da intolerância e da discriminação. Brasília, DF: Unicef. Retirado de <http://www. unicef.org/brazil/pt/Cap_02.pdf>.

Almeida, L. S., \& Lisboa, C. (2014). Habilidades sociais e bullying: Uma revisão sistemática. Contextos Clínicos, 7(1), 62-75.

Barbosa R. M. \& Araújo, C. M. (2010). Psicologia escolar no Brasil: Considerações e reflexões históricas. Estudos de Psicologia, 27(3), 393-402.

Baremblitt, G. (2012). Compêndio de análise institucional e outras correntes: Teoria e prática (6 $6^{\mathrm{a}}$ Ed.). Belo Horizonte: Editora Fundação Gregório Baremblitt/Instituto Félix Guatarri.

Bleger, J. (1992). Psico-higiene e psicologia institucional. Porto Alegre: Artes Médicas.
Bronfrenbrenner, U. (1996). A ecologia do desenvolvimento humano: Experimentos naturais e planejados. Porto Alegre: Artes Médicas. (Original publicado em 1979)

Del Prette, Z. A. P., \& Del Prette, A. (2011). Psicologia das habilidades sociais na infância: Teoria e prática $\left(5^{\mathrm{a}} \mathrm{Ed}\right)$. Petrópolis: Vozes.

Ferreira, M. C. (2010). A Psicologia social contemporânea: Principais tendências e perspectivas nacionais e internacionais. Psicologia Teoria e Pesquisa, 26, 51-64.

Franco, G. R., \& Rodrigues, M. C. (2014). Programas de intervenção na adolescência: Considerações sobre o desenvolvimento positivo do jovem. Temas em Psicologia, 22(4), 677-690.

Guimarães, G., Aerts, D., \& Câmara, S. G. (2012). A escola promotora da saúde e o desenvolvimento de habilidades sociais. Revista da Sociedade de Psicologia do Rio Grande do Sul, 12(2), 88-95.

Marinho-Araújo, C. M., \& Neves, M. M. B. J. (2007). Psicologia Escolar: Perspectivas e compromissos na formação continuada. In H. R. Campos (Org.), Formação em psicologia escolar: Realidades e perspectivas (pp. 49-67). Campinas: Alínea.

Marinho-Araújo, C. M. (2010). Psicologia escolar: Pesquisa e intervenção. Em Aberto, 23(83), 17-35.

Ministério da Saúde (2000). Manual do Multiplicador: Adolescente. Brasília: Author.

Moreira, A. P. G., \& Guzzo, R. S. L. (2014). O psicólogo na escola: Um trabalho invisível? Revista interinstitucional de Psicologia, $7(1), 42-52$.

Osório, L. C. (2003). Psicologia grupal: Uma nova disciplina para $o$ advento de uma era. Porto Alegre: Artmed.

Rodrigues, M. C., Dias, J. P., \& Freitas, M. F. R. L. (2010). Resolução de problemas interpessoais: Promovendo o desenvolvimento sociocognitivo na escola. Psicologia em Estudo, 15, 831-839. http://dx.doi.org/10.1590/S1413

Sanchez, A. I. M., \& Bertolozzi, M. R. (2007). Pode o conceito de vulnerabilidade apoiar a construção do conhecimento em saúde coletiva? Ciência e Saúde Coletiva, 12, 319-324. http://dx.doi. org/10.1590/S1413-81232007000200007

Sant'Ana, I. M., Costa, A. S., \& Guzzo, R. S. L. (2008,). Escola e vida: Compreendendo uma realidade de conflitos e contradições. Pesquisas e práticas Psicossociais 2, 302-311. DOI: 10.9788/TP2014.4-04

Scheeffer, R. (1993). Aconselhamento psicológico: Teoria e prática. São Paulo: Atlas.

Trindade, I., \& Teixeira, J. A. Carvalho. (2000). Aconselhamento psicológico em contextos de saúde e doença: Intervenção privilegiada em psicologia da saúde. Análise Psicológica, 18(1), 3-14. doi: 10.14417/ap.418.

Zimerman, D. E. (2000). Fundamentos básicos das grupoterapias $\left(2^{\mathrm{a}} \mathrm{Ed}\right)$. Porto Alegre: Artmed.

Zimerman, D. E., \& Osório, L. C. (1997). Como trabalhamos com grupos. Porto Alegre: Artes Médicas.

Recebido em 22.09.2014

Primeira decisão editorial em 13.07.2015

Versão final em 26.08.2015

Aceito em 31.08.2015 